\title{
CONFLITO DE COMPETÊNCIA ENTRE ÓRGÃOS DA SAÚDE E DA AGRICULTURA NA INSPEÇÃO E FISCALIZAÇÃO DE AÇOUGUES NO ESTADO DE SÃO PAULO
}

Conflict of jurisdiction between health and agriculture agencies in the inspection and supervision of butcheries in the state of Sao Paulo

${ }^{1}$ Universidade de São Paulo. Faculdade de Medicina Veterinária e Zootecnia. São Paulo/SP, Brasil.

${ }^{2}$ Universidade Presbiteriana Mackenzie. São Paulo/SP. Brasil.

Correspondência: Patrícia Rossi Moriconi. patricia.moriconi@usp.br

Recebido: 06/04/2019. Revisão: 20/01/2020. Aprovado: 11/02/2020. 


\section{RESUMO}

O presente artigo abordou o conflito de competência existente entre os órgãos da saúde e da agricultura no tocante à inspeção e fiscalização de açougues no estado de São Paulo, com a apresentação dos elementos responsáveis por esse conflito, as atividades rotineiras nas quais ele se torna perceptível, seus efeitos e as soluções possíveis para que seja eliminado. Foram realizadas revisão bibliográfica e pesquisa da legislação existente sobre o assunto, além de levantamento jurisprudencial no Tribunal de Justiça do Estado de São Paulo. A análise do assunto permitiu concluir que o conflito existe devido à ausência de definições e delimitações legais para as atividades desempenhadas por estabelecimentos fiscalizados por órgãos da saúde e da agricultura. Os principais prejudicados são as autoridades sanitárias, que, atuando sob insegurança jurídica, têm sua atividade suscetível a questionamentos. A própria população sofre consequências diretas desse conflito, na medida em que as garantias constitucionais ao adequado processo fiscalizatório não são observadas. A solução envolve medidas como a criação de legislações infraconstitucionais que estabeleçam limites entre as atividades de açougues e de entrepostos e a reorganização das normas infraconstitucionais já existentes; a alteração da composição do Sistema Único de Saúde, permitindo um trabalho colaborativo entre os ministérios da Saúde e da Agricultura, além de delimitação de atribuições e responsabilidades próprias de cada órgão; a criação de serviços de inspeção municipal em todos municípios; e a incorporação de parte da atividade desempenhada pelo Ministério da Agricultura, Pecuária e Abastecimento à Agência Nacional de Vigilância Sanitária.

\section{Palavras-Chave}

Direito Administrativo; Direito Constitucional; Legislação Sanitária; Legislação sobre Alimentos; Poder de Polícia.

\section{ABSTRACT}

This article addressed the existing conflict of jurisdiction between health and agriculture agencies regarding the inspection and supervision of butcheries in the state of São Paulo, with the presentation of the elements responsible for this conflict, the routine activities in which it becomes noticeable, its effects and the possible solutions for its elimination. Bibliographic review and research of existing legislation on the subject were carried out, as well as a jurisprudential survey at the Court of Justice of the State of São Paulo. The analysis of the subject made it possible to conclude that the conflict exists due to the absence of legal definitions and delimitations for the activities performed by establishments supervised by health and agriculture agencies. The main victims are the health authorities who, acting under legal uncertainty, have their activity susceptible to questions. The population itself suffers direct consequences from this conflict, insofar as the constitutional guarantees to the appropriate supervisory process are not observed. The solution involves measures such as the creation of infraconstitutional laws that establish limits between the activities of butcheries and warehouses and the reorganization of existing infraconstitutional norms; the change in the composition of the Brazilian Unified Health System, allowing collaborative work between the Ministries of Health and Agriculture, as well as the delimitation of the duties and responsibilities of each agency; the creation of municipal inspection services in all municipalities; and the incorporation of part of the activity performed by the Ministry of Agriculture, Livestock and Food Supply to the National Health Surveillance Agency.

\section{Keywords}

Administrative Law; Constitutional Law; Health Surveillance Legislation; Food Law; Police Power. 
Competência dos órgãos da saúde e da agricultura na inspeção e fiscalização de açougues em São Paulo

\section{Introdução}

A fiscalização e a inspeção da industrialização de produtos de origem animal são obrigatórias no Brasil no mínimo desde 1950, com a promulgação da Lei n. 1.283/1950 ${ }^{1}$. Essas atividades são de competência legal do Ministério da Agricultura, Pecuária e Abastecimento (MAPA) ou de órgãos estaduais e municipais correspondentes, na dependência do âmbito de comercialização dos produtos. Dentre esses produtos, estão carnes e os produtos cárneos, frequentemente comercializados à população por estabelecimento denominado açougue ou casa de carnes (pertencentes ao ramo varejista), cuja fiscalização atualmente é de competência das secretarias de Saúde, por meio dos serviços de vigilância sanitária.

Embora as legislações sanitárias tragam explicitamente essa delimitação de competência, na prática a existência de dois órgãos diferentes de normatização e fiscalização gera conflito. Este artigo tem como objetivo apresentar, no âmbito territorial do estado de São Paulo, os elementos responsáveis por esse conflito e em quais práticas adotadas na rotina dos açougues ele ocorre, sendo o primeiro trabalho a fazê-lo. Além disso, objetiva discutir essa questão face à legislação sanitária existente e apresentar propostas para solucioná-la.

\section{Instâncias de fiscalização sanitária e origem do conflito}

Em 1989, a promulgação da Lei n. 7.889/1989² desfederalizou a inspeção de produtos de origem animal no Brasil, determinando competências de fiscalização de acordo com o âmbito de comercialização dos produtos. Essa lei determinou que a fiscalização fosse realizada pelo MAPA se as carnes ou os produtos cárneos industrializados fossem comercializados em todo o país; pela Secretaria de Agricultura estadual, caso esses alimentos fossem comercializados dentro do estado onde foram produzidos; e pela Secretaria ou Departamento de Agricultura municipal, se fossem comercializados apenas dentro do município onde ocorreu a produção.

No estado de São Paulo, essa fiscalização é realizada atualmente pela Secretaria de Agricultura e Abastecimento (SAA), por meio do Departamento de Defesa Agropecuária, que instituiu seu Serviço de Inspeção ${ }^{3}$. Já com relação à esfera municipal de inspeção, nem todos os municípios dispõem de tal serviço, sendo exemplos a própria capital, Campinas e Sumaré. Outros o possuem, mas ele é subordinado à

\footnotetext{
${ }^{1}$ BRASIL. Lei n. 1.283, de 18 de dezembro de 1950. Dispõe sobre a inspeção industrial e sanitária dos produtos de origem animal. Disponível em: http://www.planalto.gov.br/ccivil_03/Leis/L1283.htm. Acesso em: 26 mar. 2019.

${ }^{2}$ BRASIL. Lei n. 7.889, de 23 de novembro de 1989. Dispõe sobre a Inspeção Sanitária e Industrial dos Produtos de Origem Animal, e dá outras Providências. Disponível em: http://www.agricultura.gov.br/ assuntos/inspecao/produtos-animal/sisbi-1/legislacao/lei-7889.pdf. Acesso em: 17 jul. 2018.

${ }^{3}$ SÃO PAULO. Lei n. 8.208, de 30 de dezembro 1992. Dispõe sobre a prévia inspeção sanitária dos produtos de origem animal, institui taxas e dá outras providências. Disponível em: https://www.al.sp.gov.br/ norma/16431. Acesso em: 17 jul. 2018.
} 
Secretaria Municipal da Saúde - o que está em desacordo com a Lei n. 7.889/1989 -, como é o caso do município de Itu ${ }^{4}$. Isso ocorre porque determinados municípios desejam ter o serviço, mas não contam com Secretaria da Agricultura em seu quadro administrativo. Outra situação existente é a vinculação do Serviço de Inspeção de produtos de origem animal à Secretaria de Agricultura, como é o caso de Pindamonhangaba ${ }^{5}$, situação que vai ao encontro da Lei n. 7.889/1989.

Já no ano de sua promulgação, a Lei 7.889/1989 previa que as inspeções sanitárias em estabelecimentos varejistas e atacadistas que comercializassem produtos de origem animal deveriam ser realizadas por órgãos de saúde pública dos estados e territórios.

No ano seguinte, a Lei n. 8.080/19906 , que criou o Sistema Único de Saúde (SUS), também passou a regular as ações de inspeção e fiscalização de alimentos, desempenhadas pelos serviços de vigilância sanitária de alimentos vinculados a órgãos da saúde nas esferas federal, estadual e municipal. $\mathrm{O}$ artigo $6^{\circ}$, inciso VIII, dessa lei determina que estão inclusas no campo de atuação do SUS a fiscalização e a inspeção de alimentos, água e bebidas para consumo humano. No entanto, ao publicar essa norma, o legislador não mencionou no texto legal a fiscalização já praticada pelos órgãos da agricultura nas indústrias de produtos de origem animal.

Após a avaliação da legislação vigente (Lei n. 1.283/1950, Lei n. 7.889/1989 e Lei n. 8.0801990) frente aos conceitos jurídicos da supremacia constitucional, do fenômeno de recepção das normas e do controle de constitucionalidade, Carvalho ${ }^{7}$, Pereira e Moura ${ }^{8}$ e Lacerda-Filho ${ }^{9}$ sugerem que as normas referentes à fiscalização feita pelos órgãos da agricultura não foram recepcionadas pela Constituição Federal de 1988 (CF/88), o que exclui a competência desses órgãos de atuar na fiscalização de alimentos.

\footnotetext{
${ }^{4}$ ITU. Lei n. 1.568, de 18 de outubro de 2018. Dispõe sobre a criação do serviço de inspeção municipal de origem animal, institui taxas e dá outras providências. Disponível em: https://leismunicipais.com.br/a/sp/i/ itu/lei-ordinaria/2013/156/1568/lei-ordinaria-n-1568-2013-dispoe-sobre-a-criacao-do-servico-de-inspeca o-municipal-de-origem-animal-e-vegetal-institui-taxas-e-da-outras-providencias. Acesso em: 17 jul. 2018.

${ }^{5}$ PINDAMONHANGABA. Lei n. 4.536, de 21 de dezembro de 2006. Dispõe sobre a criação do serviço de inspeção municipal SIM, na forma que especifica. Disponível em: https://camara-municipal-da-pindamonh angaba.jusbrasil.com.br/legislacao/497370/lei-4536-06. Acesso em: 17 jul. 2018.

${ }^{6}$ BRASIL. Lei n. 8080, de 19 de setembro de 1990. Dispõe sobre as condições para a promoção, proteção e recuperação da saúde, a organização e o funcionamento dos serviços correspondentes e dá outras providências. Disponível em: http://www.planalto.gov.br/ccivil_03/leis/L8080.htm. Acesso em: 17 jul. 2018.

${ }^{7}$ CARVALHO, Patrícia Borges. Conflito de competências na fiscalização de alimentos de origem animal no Brasil: uma análise da legislação em vigor no Brasil. Revista de Direito Sanitário, São Paulo, v. 5, n. 1, p. 18-39, mar. 2004. Disponível em: http://www.revistas.usp.br/rdisan/article/view/80885. Acesso em: 19 jul. 2018. https://doi.org/10.11606/issn.2316-9044.v5i1p18-39.

${ }^{8}$ PEREIRA, Gúbio Dias; MOURA, Luís Antônio de. Conflito de competências entre os Ministérios da Saúde e da Agricultura na fiscalização de produtos alimentícios no Brasil. Revista Tempus- Acta de Saúde Coletiva, v. 7, n. 1, p. 197-210, 2013. Disponível em: http://www.tempusactas.unb.br/index.php/tempus/article/ view/1287. Acesso em: 19 jul. 2018. http://dx.doi.org/10.18569/tempus.v7i1.1287.

${ }^{9}$ LACERDA-FILHO, Francisco Pereira. Conflito de atribuições no controle e fiscalização de alimentos de origem animal no Brasil, a luz da Constituição Federal. Cadernos Ibero-americanos de Direito Sanitário, v. 5, n. 4, p. 27-41, dez. 2016. Disponível em: https://www.cadernos.prodisa.fiocruz.br/index.php/cadernos/article/ view/251. Acesso em: 19 jul. 2018. http://dx.doi.org/10.17566/ciads.v5i4.251.
} 
Competência dos órgãos da saúde e da agricultura na inspeção e fiscalização de açougues em São Paulo

Na prática, em respeito ao artigo $7^{\circ}$ do Decreto n. 9.013/2017 $7^{10}$ - que determina que a realização de inspeção e fiscalização sanitária por órgão da agricultura isenta o estabelecimento da necessidade de qualquer outra fiscalização sanitária -, observa-se que os órgãos da agricultura realizam a fiscalização apenas de estabelecimentos que fabricam e industrializam produtos de origem animal, isentando esses estabelecimentos da fiscalização da saúde. Por outro lado, para as demais empresas, os órgãos da saúde são os responsáveis pela regulação e fiscalização. Por exemplo, indústrias que fazem o envase de água e a industrialização de matérias vegetais para produzir massas, biscoitos e pães, além de estabelecimentos que comercializam esses produtos, como padarias e lanchonetes, são fiscalizadas pelos serviços de vigilância sanitária. Embora pareça simples dividir a inspeção e a fiscalização sanitárias de alimentos entre dois órgãos diferentes, na prática a falta de definição clara de conceitos e de delimitação legal para a atuação de cada órgão é responsável pela ocorrência de diversos conflitos no dia a dia da fiscalização de alimentos. A atividade de açougue é uma das mais prejudicadas por esse limbo legislativo. Os conflitos referentes à produção e comercialização de produtos cárneos serão expostos e analisados a seguir.

\section{Definições de açougue e de atividade fabril}

A classificação de estabelecimentos que produzem produtos de origem animal (POA) está embasada na legislação da agricultura - Decreto n. 9.013/2017 e Resolução SSA n. 24/1994 ${ }^{11}$-, e não nos códigos da Classificação Nacional de Atividades Econômicas (CNAE) definidos pela Comissão Nacional de Classificação (Concla) ${ }^{12}$, pertencente ao Instituto Brasileiro de Geografia e Estatística (IBGE). As secretarias de Saúde dos municípios paulistas seguem as definições deste instituto, a partir da Portaria n. 01/2020 do Centro de Vigilância Sanitária (CVS) ${ }^{13}$. Desse modo, no âmbito do estado de São Paulo, a atividade de entreposto de carnes e derivados, segundo o artigo 25 da Resolução SAA n. 24/1994, envolve o recebimento, a guarda, a conservação, o acondicionamento e a distribuição das diversas espécies de carnes frescas ou frigorificadas e de outros produtos animais vendidos em açougues, podendo dispor ou não de dependências anexas para industrialização, a juízo da inspeção. $O$ mesmo ocorre no âmbito

\footnotetext{
${ }^{10}$ BRASIL. Decreto n. 9.013, de 29 de março de 2017. Regulamenta a Lei $n^{\circ} 1.283$, de 18 de dezembro de 1950, e a Lei $n^{\circ} 7.889$, de 23 de novembro de 1989, que dispõem sobre a inspeção industrial e sanitária de produtos de origem animal. Disponível em: http://www.planalto.gov.br/ccivil_03/_ato2015-2018/2017/ decreto/d9013.htm. Acesso em: 19 jul. 2018.

${ }^{11}$ SÂO PAULO. Resolução SAA n. 24, de 01 de agosto de 1994. Dispõe sobre as normas técnicas de produção e classificação dos produtos de origem animal e as relativas às atividades de fiscalização e inspeção dos produtos de origem animal. Disponível em: https://www.defesa.agricultura.sp.gov.br/legislacoes/ resolucao-saa-24-de-01-08-1994,33.html. Acesso em: 19 jul. 2018.

${ }^{12}$ INSTITUTO BRASILEIRO DE GEOGRAFIA E ESTATÍSTICA - IBGE. Comissão Nacional de Classificação CONCLA. Disponível em: https://cnae.ibge.gov.br. Acesso em: 19 jul. 2018.

${ }^{13}$ SÃO PAULO. Portaria CVS n. 1, de 22 de julho de 2020. Disciplina, no âmbito do Sistema Estadual de Vigilância Sanitária - Sevisa, o licenciamento dos estabelecimentos de interesse da saúde e das fontes de radiação ionizante, e dá providências correlatas. Disponível em: http: http://200.144.0.250/download/ site/E_PT-CVS-01_220720\%20-\%20RET_190421\%20-\%20SITE.pdf. Acesso em: 19 jul. 2018.
} 
federal, porém o estabelecimento é denominado unidade de beneficiamento de carne e produtos cárneos (art. 17, II, Decreto n. 9.013/2017). Por outro lado, a Portaria CVS n. 01/2020 define açougue com base na Concla ${ }^{14}$ como o estabelecimento comercial varejista de carnes de bovino, suíno, caprino, ovino, equídeo, aves e pequenos animais, frescas, frigorificadas e/ou congeladas. Na atividade de açougue, portanto, não está prevista a industrialização de produtos, diferentemente da atividade de entreposto. A categoria de entreposto, por sua vez, não foi compreendida pela Concla ${ }^{15}$. De acordo com o disposto no site do IBGE ${ }^{16}$, o comércio varejista (dentro do qual está inserida a atividade de açougue) não deve realizar transformações significativas nos alimentos e, geralmente, representa o elo final na cadeia de distribuição. Etapas como fracionamento, que são praticadas pelos açougues durante a desossa, não são entendidas pelo instituto como transformação. Além disso, o IBGE entende que o comércio varejista revende mercadorias que não sofreram modificações, principalmente ao público em geral, para consumo doméstico.

Por outro lado, a definição da palavra "industrialização" não é facilmente encontrada na literatura, cabendo à legislação tributária fazê-la. A Lei n. 4.502/1964 ${ }^{17}$, em seu artigo $3^{\circ}$, parágrafo único, define industrialização como "qualquer operação que resulte na alteração da natureza, funcionamento, utilização, acabamento ou apresentação do produto". Este conceito corrobora o estabelecido no Decreto n. $7.212 / 2010^{18}$, cujo artigo $4^{\circ}$ exemplifica situações que devem ser entendidas como industrialização. Dentre os exemplos, são importantes: "a [atividade] que, exercida sobre matérias-primas ou produtos intermediários importe na obtenção de espécie nova (transformação) (inciso I); "a que importe em modificar, aperfeiçoar ou, de qualquer forma, alterar o funcionamento, utilização, acabamento ou a aparência do produto (beneficiamento)" (inciso II); "a que consista na reunião de produtos, peças ou partes e de que resulte um novo produto ou unidade autônoma [...] (montagem)" (inciso III); e "a que importe em alterar a apresentação do produto, pela colocação da embalagem, ainda que em substituição da original, salvo quando a embalagem colocada se destine apenas ao transporte da mercadoria (acondicionamento ou reacondicionamento)" (inciso IV). Por fim, ressalta-se que o artigo $5^{\circ}$ desse mesmo decreto exclui do conceito de industrialização o preparo de produtos alimentares

\footnotetext{
${ }^{14}$ INSTITUTO BRASILEIRO DE GEOGRAFIA E ESTATÍSTICA - IBGE. Comissão Nacional de Classificação CONCLA, cit.

${ }^{15}$ INSTITUTO BRASILEIRO DE GEOGRAFIA E ESTATÍSTICA - IBGE. Comissão Nacional de Classificação CONCLA. CNAE-Subclasses. Disponível em: https://concla.ibge.gov.br/busca-online-cnae.html?view=subcl asse\&tipo $=$ cnae\&versao=10\&subclasse $=4722901$. Acesso em: 19 jul. 2018.

${ }^{16} / \mathrm{ld}$. Ibid.

${ }^{17}$ BRASIL. Lei n. 4.502, de 30 de novembro de 1964. Dispõe sobre o Imposto de Consumo e reorganiza a Diretoria de Rendas Internas. Disponível em: http://www2.camara.leg.br/legin/fed/lei/1960-1969/lei4502-30-novembro-1964-376851-publicacaooriginal-1-pl.html. Acesso em: 19 jul. 2018.

${ }^{18}$ BRASIL. Decreto n. 7.212, de 15 de junho de 2010. Regulamenta a cobrança, fiscalização, arrecadação e administração do Imposto sobre Produtos Industrializados - IPI. Disponível em: http://www.planalto.gov.br/ ccivil_03/_ato2007-2010/2010/decreto/d7212.htm. Acesso em: 19 jul. 2018.
} 
Competência dos órgãos da saúde e da agricultura na inspeção e fiscalização de açougues em São Paulo

que estão fora de embalagem de apresentação em estabelecimentos comerciais, caso esses produtos sejam destinados à venda direta ao consumidor.

\section{Caracterização do conflito}

As definições de açougue e de atividade fabril são vagas, o que leva os agentes fiscalizatórios a diversos questionamentos quanto à pertinência da realização de algumas práticas pelos açougues. Soma-se a isso o fato de as legislações existentes não delimitarem claramente quais atividades podem ser desempenhadas pelo varejo e quais devem ser exclusivas da indústria de alimentos. Por exemplo, a embalagem e o empacotamento de carnes ou produtos cárneos, de acordo com as legislações tributárias, são consideradas parte de um processo industrial, exceto se o invólucro colocado se destina apenas ao transporte do produto. No entanto, se for considerada a Resolução da Diretoria Colegiada (RDC) n. 259/2002 da Agência Nacional de Vigilância Sanitária (Anvisa) ${ }^{19}$, todo alimento embalado na ausência do cliente necessita apresentar rotulagem - atividade que, na maioria das vezes, os responsáveis por estabelecimentos varejistas não possuem conhecimento técnico para desempenhar.

Com relação à embalagem a vácuo ou sob atmosfera modificada, entende-se, pelas legislações tributárias, que são consideradas atividades fabris, visto que se enquadram nos incisos I e II do Decreto n. 7.212/2010. Entretanto, essa questão não é apresentada claramente em nenhuma legislação sanitária, ficando a autoridade legalmente desamparada para coibir essa prática, perpetrada por muitas casas de carnes em diversas cidades do estado. Vale ressaltar que a modificação da atmosfera gasosa de produtos cárneos é uma prática bastante complexa e que pode intensificar o risco do desenvolvimento de micro-organismos patogênicos ${ }^{20}$.

Outras práticas comuns em açougues são as de fracionamento, reembalagem e rotulagem de carnes e produtos cárneos. No entanto, o estabelecimento varejista que embala e rotula esses produtos pode incorrer em fraude por falsificações. De acordo com a RDC n. 259/2002, da Anvisa, no rótulo do alimento, devem constar informações sobre a origem do produto (inclusive o número de registro do estabelecimento junto ao órgão fiscalizador competente). Ao inserir informações próprias, o açougue pode incorrer em falsificação, segundo o artigo 504, segundo parágrafo, inciso II, alínea “f”, do Decreto Federal n. 9.013/2017, pois pode induzir o consumidor a erro, apondo sua marca em produto fabricado por outra empresa

\footnotetext{
${ }^{19}$ AGÊNCIA NACIONAL DE VIGILÂNCIA SANITÁRIA - ANVISA. Resolução da Diretoria Colegiada n. 259, de 20 de setembro de 2002. Aprova o Regulamento Técnico sobre Rotulagem de Alimentos Embalados. Disponível em: http://portal.anvisa.gov.br/documents/33880/2568070/RDC_259_2002.pdf/e40c2ecb6be6-4a3d-83ad-f3cf7c332ae2. Acesso em: 19 dez. 2018.

${ }^{20}$ MANTILLA, Samira Pirola Santos; MANO, Sergio Borges; VITAL, Hélio de Carvalho; FRANCO, Robson Maia. Atmosfera modificada na conservação de alimentos. Revista Acadêmica Ciências Agrárias e Ambientais, v. 8, n. 4, p. 437-448, 2010. Disponível em: https://periodicos.pucpr.br/index.php/cienciaanimal/article/ viewFile/11000/10397. Acesso em: 05 dez. 2019.
} 
(por exemplo, por abatedouros e frigoríficos ou entrepostos). Mesmo que o açougue venha a utilizar informações da indústria de origem, poderia ele inserir em seus rótulos informações de outra empresa sem lhe solicitar autorização?

No meio desse conflito legislativo, na opinião de $\operatorname{Tesser}^{21}$, os responsáveis por açougues buscam, assim como outros atores na cadeia produtiva de carnes no Brasil, melhorar a qualidade de seus produtos, satisfazendo um consumidor cada vez mais exigente. A necessidade de melhorar a qualidade do produto concorda com a prática de comercializar as carnes envoltas em embalagens, as quais têm a finalidade de proteger os alimentos de qualquer tipo de contaminação ${ }^{22}$, o que melhora a apresentação e a sanidade do produto. Como, então, vedar essa prática sendo que ela não é claramente proibida? Como leciona Hely Lopes Meirelles ${ }^{23}$ : "Na Administração Pública não há liberdade nem vontade pessoal. Enquanto na administração particular é lícito fazer tudo que a lei não proíbe, na Administração Pública só é permitido fazer o que a lei autoriza".

Outra questão que gera conflito é a dos produtos cárneos temperados. Embora a legislação tributária entenda como industrialização a obtenção de espécies novas, o Decreto Estadual n. 45.248/2000 ${ }^{24}$, em seu artigo $1^{\circ}$, parágrafo $2^{\circ}$, faculta aos açougues a realização de preparo e tempero de carnes frescas, desde que apresentem certificado de capacitação de funcionário à autoridade sanitária. Ora, não deveria ser essa atividade entendida como transformação e, portanto, industrialização? Soma-se a isso o fato de a Anvisa, até há pouco tempo, permitir por omissão a agregação de aditivos em carnes por açougues ${ }^{25}$. Aditivos alimentares são legalmente definidos

\footnotetext{
${ }^{21}$ TESSER, Elisa Scheid. O uso de diferentes tipos de embalagem na conservação de carnes bovinas. 2009. Monografia (Graduação) - Faculdade de Veterinária, Universidade Federal do Rio Grande do Sul, Porto Alegre, 2009.

${ }^{22}$ AGÊNCIA NACIONAL DE VIGILÂNCIA SANITÁRIA - ANVISA. Resolução da Diretoria Colegiada n. 91, de 11 de maio de 2001. Aprova o Regulamento Técnico - Critérios Gerais e Classificação de Materiais para Embalagens e Equipamentos em Contato com Alimentos. Disponível em: http://portal.anvisa.gov.br/ documents/10181/2718376/(1)RDC_91_2001_COMP.pdf/fb132262-e0a1-4a05-8ff7-bc9334c18ad3. Acesso em: 20 dez. 2018.

${ }^{23}$ MIRELLES, Hely Lopes. Direito administrativo brasileiro. 42. ed. São Paulo: Malheiros, 2016.

${ }^{24}$ SÃO PAULO. Decreto n. 45.248, de 28 de setembro de 2000. Dá nova redação ao artigo 461 do Regulamento a que se refere o artigo 22 do Decreto-Lei n. 211, de 30 de março de 1970, aprovado pelo Decreto n. 12.342, de 27 de setembro de 1978, que dispõe sobre normas de promoção, preservação e recuperação da saúde no campo de competência da Secretaria da Saúde e dá providência correlata. Disponível em: https://www.al.sp.gov.br/repositorio/legislacao/decreto/2000/decreto-45248-28.09.2000.html. Acesso em: 20 dez. 2018.

${ }^{25}$ MINISTÉRIO DA SAÚDE. Portaria n. 1.004/98, de 11 de dezembro de 1998. Aprova o Regulamento Técnico: "Atribuição de Função de Aditivos, Aditivos e seus Limites Máximos de uso para a Categoria 8 Carne e Produtos Cárneos". Disponível em: http://portal.anvisa.gov.br/documents/33916/391619/Port aria $+n \% C 2 \% B A+1004 \% 2 C+d e+11+d e+d e z e m b r o+d e+1998 . p d f / 41 e 1 b c 8 f-b 276-4022-9 a f b-f f 0 b b 3 c 12 c$ Oc. Acesso em: 19 dez. 2018. Observação: esta legislação foi revogada e substituída, em 18 de março de 2019, pela RDC n. 272/2019 (AGÊNCIA NACIONAL DE VIGILÂNCIA SANITÁRIA - ANVISA. Resolução da Diretoria Colegiada n. 272, de 14 de março de 2019. Estabelece os aditivos alimentares autorizados para uso em carnes e produtos cárneos. Disponível em: https://www.in.gov.br/web/guest/materia/-/ asset_publisher/KujrwOTZC2Mb/content/id/67378977/do1-2019-03-18-resolucao-da-diretoria-colegiad a-rdc-n-272-de-14-de-marco-de-2019-67378770. Acesso em: 16 abr. 2021.
} 
Competência dos órgãos da saúde e da agricultura na inspeção e fiscalização de açougues em São Paulo

como ingredientes que têm por função "modificar as características físicas, químicas, biológicas ou sensoriais", conforme a Portaria da Secretaria de Vigilância Sanitária do Ministério da Saúde (SVS/MS) n. 540/1997²6. Portanto, a utilização de aditivos deve ser considerada parte de um processo industrial.

Assim, coexistem no mercado de consumo dois tipos de produtos temperados: os que são fabricados pela indústria e possuem selo de inspeção, seja ele estadual, municipal ou federal; e os que são produzidos pelos estabelecimentos varejistas e que são comercializados sem nenhum tipo de inspeção prévia no estado de São Paulo.

Outra questão conflituosa refere-se à moagem de carnes em estabelecimentos varejistas. Antigamente proibida no Estado de São Paulo pelo Decreto n. 45.248/2000, recentemente foi motivo de discussão nas câmaras municipais e passou a ser permitida em um número crescente de municípios do estado, como São Paulo $^{27}$ e Campinas ${ }^{28}$. Por outro lado, esse produto também é regulado por normativa própria expedida pelo $\mathrm{MAPA}^{29}$, a qual leva em conta a necessidade de dispor acerca da industrialização dos produtos de origem animal. Considerando que, segundo as legislações municipais (Lei n. 16.386/2016, de São Paulo, e Lei n. 15.344/2016, de Campinas), é facultado ao consumidor escolher que a moagem seja realizada à sua vista, a carne moída no comércio varejista que já esteja embalada e disponível para venda nos balcões de autosserviço deverá, de acordo com a RDC n. 259/2002 da Anvisa, apresentar rotulagem. Desse modo, coexistem atualmente duas situações: a comercialização de um produto industrializado, embalado e com selo de registro no Ministério da Agricultura; e a comercialização de um produto moído dentro da própria casa de carnes e que, segundo a nova legislação, também pode ser embalado, mas sem selo de registro no Ministério da Agricultura por ter sofrido processamento posterior no varejo. Soma-se a esse conflito a questão da adulteração já apontada anteriormente, caso o estabelecimento varejista venha a apor rótulo com registro da indústria de origem da carne em seu produto. Outra situação importante de ser

\footnotetext{
${ }^{26}$ MINISTÉRIO DA SAÚDE. Secretaria de Vigilância Sanitária. Portaria SVS/MS n. 540, de 27 de outubro de 1997. Aprova o Regulamento Técnico: Aditivos Alimentares - definições, classificação e emprego. Disponível em: http://bvsms.saude.gov.br/bvs/saudelegis/svs1/1997/prt0540_27_10_1997.html. Acesso em: 16 abr. 2021.

${ }^{27}$ SÃO PAULO. Lei n. 16.386, de 3 de fevereiro de 2016. Dispõe sobre a identidade e as características mínimas de qualidade a que o produto cárneo, denominado Carne Moída, obedecerá quando destinado à venda, manipulado e embalado no comércio varejista de carnes e dá outras providências. Disponível em: http://www.docidadesp.imprensaoficial.com.br/RenderizadorPDF.aspx?ClipID=3HB1EN9PE6G8Ge8BJGD 27QJG5ES. Acesso em: 20 dez. 2018

${ }^{28}$ CAMPINAS. Lei n. 15.344 , de 16 de novembro de 2016. Dispõe sobre a identidade e as características mínimas de qualidade a que o produto cárneo, denominado Carne Moída, obedecerá quando destinado à venda, manipulado e embalado no comércio varejista de carnes e dá outras providências. Disponível em: http://www.saude.campinas.sp.gov.br/saude/lista_legislacoes/legis_2016/LM_15344_2016_11_16. pdf. Acesso em: 30 abr 2021.

${ }^{29}$ MINISTÉRIO DA AGRICULTURA, PECUÁRIA E ABASTECIMENTO - MAPA. Secretaria de Defesa Agropecuária. Instrução Normativa n. 83, de 21 de novembro de 2003. Aprovar os Regulamentos Técnicos De Identidade e Qualidade De Carne Bovina Em Conserva (Corned Beef) e Carne Moída De Bovino. Disponível em: http:// www2.aladi.org/nsfaladi/normasTecnicas.nsf/09267198f1324b64032574960062343c/4207980b27b 39cf903257a0d0045429a/\$FILE/IN\%20N\%c2\%ba\%2083-2003.pdf. Acesso em: 16 abr. 2021.
} 
mencionada é a adição de sulfito de sódio em carnes moídas por estabelecimentos varejistas, fraude realizada para mascarar as reais condições da matéria-prima, a qual pode já apresentar sinais de deterioração ${ }^{30}$. Essa prática certamente foi favorecida pela promulgação das legislações que autorizam a moagem fora da vista do consumidor.

Assunto relacionado à pré-moagem de carnes e que também gera conflito éo preparo de produtos derivados de carnes (hambúrguer, almôndega, quibe e cafta) por açougues. Alguns desses produtos até possuem Regulamento Técnico de Identidade e Qualidade definido pelo MAPA, como é o caso dos três primeiros ${ }^{31}$; entretanto, em que pese tal normativa, é possível encontrar nas gôndolas dos supermercados, principalmente em cidades do interior do estado, quibes e almôndegas industrializados sendo comercializados sem registro no órgão da agricultura. Nesses casos, as empresas produtoras são indústrias que se enquadram nas atividades fiscalizadas por órgãos da saúde. Além dessas indústrias, os açougues também produzem e manipulam tais produtos. Entretanto, há de se considerar que não ocorre transformação significativa desses produtos durante sua confecção, como cita a legislação tributária (Decreto n. 7.212/2010), visto que, basicamente, são constituídos de carne pré-moída (autorizada em alguns municípios, como citado anteriormente) que é temperada e moldada em formato diferente. Embora a legislação municipal de São Paulo ${ }^{32}$ proíba claramente o comércio varejista de carnes de preparar produtos com carne moída, a legislação estadual correspondente ${ }^{33}$ nem ao menos possui artigos específicos sobre essa atividade econômica. $\mathrm{O}$ mesmo acontece com o produto denominado "espetinho". Existem espetinhos que possuem registro nos órgãos da agricultura. No entanto, à luz das legislações da saúde, esse produto é composto basicamente de carne temperada, cuja produção é permitida aos açougues pelo Decreto n. 45.248/2000, sendo sua única particularidade a inserção de uma haste de madeira.

Outros alimentos frequentemente envolvidos no conflito fiscalizatório entre órgãos da agricultura e da saúde são as linguiças e as carnes salgadas. Embora exista

\footnotetext{
${ }^{30}$ BONFADA, Daniele Hübner; KINDLEIN, Liris; VILARINHO, Rita Cássia; BERGMANN, Guiomar Pedro. Presença de sulfito de sódio e sua influência nas características físico-químicas e microbiológicas de carnes bovinas moídas resfriadas moídas resfriadas. Acta Scientiae Veterinariae, v. 40, n. 2, p. 1036, 2012. Disponível em: http://www.ufrgs.br/actavet/40-2/PUB\%201036.pdf. Acesso em: 03 dez. 2019.

${ }^{31}$ MINISTÉRIO DA AGRICULTURA, PECUÁRIA E ABASTECIMENTO - MAPA. Secretaria de Defesa Agropecuária. BRASIL. Instrução Normativa n. 20, de 31 de julho de 2000. Aprova os Regulamentos Técnicos de Identidade e Qualidade de Almôndega, de Apresuntado, de Fiambre, de Hambúrguer, de Kibe, de Presunto Cozido e de Presunto. Disponível em: https://pesquisa.in.gov.br/imprensa/jsp/visualiza/index.jsp?data=0 3/08/2000\&jornal=1\&pagina=55\&totalArquivos=88. Acesso em: 16 abr. 2021.

${ }^{32}$ SÃO PAULO. Portaria n. 2.619, de 06 de dezembro de 2011. Aprovar o Regulamento de Boas Práticas e de Controle de condições sanitárias e técnicas das atividades relacionadas à importação, exportação, extração, produção, manipulação, beneficiamento, acondicionamento, transporte, armazenamento, distribuição, embalagem e reembalagem, fracionamento, comercialização e uso de alimentos - incluindo águas minerais, águas de fontes e bebidas -, aditivos e embalagens para alimentos. Disponível em: https://www.prefeitura. sp.gov.br/cidade/secretarias/upload/chamadas/portaria_2619_1323696514.pdf. Acesso em: 20 dez. 2018.

${ }^{33}$ SÂO PAULO. Portaria CVS n. 5, de 9 de abril de 2013. Aprova o regulamento técnico sobre boas práticas para estabelecimentos comerciais de alimentos e para serviços de alimentação, e o roteiro de inspeção. Disponível em: http://www.cvs.saude.sp.gov.br/up/PORTARIA\%20CVS-5_090413.pdf. Acesso em: 20 dez. 2018.
} 
Competência dos órgãos da saúde e da agricultura na inspeção e fiscalização de açougues em São Paulo

um regulamento técnico do Ministério da Agricultura, Pecuária e Abastecimento que define e guia a fabricação de linguiças ${ }^{34}$, claramente as tratando como produto cárneo industrializado, a facilidade tanto na obtenção de envoltórios por açougues quanto no próprio processo de fabricação perpetua a prática da fabricação de linguiça nesses estabelecimentos. Soma-se a isso o fato de não existir, na legislação sanitária referente ao comércio varejista, proibição clara e expressa à realização dessa atividade.

Com relação à salga de carnes, consta no Decreto Federal n. 9.013/2017 uma definição do produto “charque”. Embora seja uma produção relativamente simples (carne adicionada de sal), o que torna frequente seu preparo em açougues, há de se considerar que o processo de fabricação desse produto imputa modificações físico-químicas (no parâmetro de atividade de água, por exemplo) e microbiológicas (favorecendo o desenvolvimento de certos micro-organismos) ${ }^{35}$, devendo sua produção ser entendida como industrialização à luz do Decreto n. 7.212/2010.

É importante mencionar, ainda, que se escuta de estudiosos da área de alimentos que, se um determinado produto alimentício possuir mais de $50 \%$ de produtos de origem animal em sua constituição, deve ter registro nos órgãos da agricultura. No entanto, tal entendimento não encontra nenhum fundamento em texto legal.

Por fim, também permanece conflituoso o abate clandestino de animais, prática ainda comum em muitas cidades no estado de São Paulo, principalmente de aves. A vigilância sanitária, por vezes, exime-se dessa atribuição fiscalizatória, justificando que o abate de animais deve ser fiscalizado por órgão da agricultura ${ }^{36}$, como dispõe a Lei n. 1.283/1950, mesmo quando a atividade ocorre em empresas com CNAEs referentes a órgãos da saúde. Os órgãos da agricultura, no entanto, geralmente consideram que é sua atribuição apenas o controle do abate realizado em estabelecimentos por eles registrados, o que faz com que o volume de abate clandestino no país ainda seja considerado alto ${ }^{37}$. Além disso, mesmo quando ações conjuntas são combinadas entre os dois órgãos, a competência da autuação, nesses casos, não é acertada.

\footnotetext{
${ }^{34}$ MINISTÉRIO DA AGRICULTURA, PECUÁRIA E ABASTECIMENTO - MAPA. Secretaria de Defesa Agropecuária. Instrução normativa n. 04, de 31 de março de 2000. Aprova os Regulamentos Técnicos de Identidade e Qualidade de Carne Mecanicamente Separada, de Mortadela, de Lingüiça e de Salsicha, em conformidade com os Anexos desta Instrução Normativa. Disponível em: https://pesquisa.in.gov.br/imprensa/jsp/visualiza/ index.jsp?data=05/04/2000\&jornal=1\&pagina=54\&totalArquivos=73. Acesso em: 16 abr. 2021.

${ }^{35}$ ABRANTES, Maria Rociene; SOUSA, Ana Carina Praciano; ARAÚJO, Nikolay Kiev Saraiva de; SOUSA, Êlika Suzianny de; OLIVEIRA, Adriene Rosceli Menezes de; SILVA, Jean Berg Alves da. Avaliação microbiológica de carne de charque produzida industrialmente. Arquivos do Instituto Biológico, v. 81, n. 3, p. 282-285, 2014. Disponivel em: http://www.scielo.br/pdf/aib/v81n3/1808-1657-aib-81-03-00282.pdf. Acesso em: 05 dez 2019. https://dx.doi.org/10.1590/1808-1657000942012.

${ }^{36}$ MOURA, Luís Antônio. Qualidade bacteriológica de carcaças de aves, sob diferentes condições das operações de abate, comercializadas em feiras urbanas do Distrito Federal. 2012. Tese (Doutorado) Escola de Veterinária e Zootecnia, Universidade Federal de Goiás, Goiânia, 2012.

${ }^{37}$ BÁNKUTI, Ferenc Istvan. Entraves e incentivos ao abate clandestino de bovinos no Brasil. 2002. Dissertação (Mestrado) - Programa de Pós-Graduação em Engenharia de Produção da Universidade Federal de São Carlos, 2002. Disponível em: http://www.gepai.dep.ufscar.br/pdfs/1088521715_Ferenc_OK.pdf.
} 


\section{Efeitos do conflito}

A existência de lacunas legais e a divisão inexata das atribuições dos órgãos da saúde e da agricultura quanto à fiscalização e à inspeção dos produtos de origem animal no Brasil têm diversos efeitos negativos, tanto para os consumidores quanto para os agentes fiscalizatórios e para os fiscalizados. Costa $^{38}$ diz que, no lado dos consumidores, essa ineficiência normativa pode gerar riscos à saúde pública, pois leva o ente fiscalizador a não adotar determinadas medidas que são de proteção à saúde. Essa posição é compartilhada por Carvalho ${ }^{39}$, que cita em seu trabalho que a omissão por parte da administração pública municipal e estadual ocorre devido ao desconhecimento do limite de atuação de cada órgão. Além disso, outro efeito desse conflito é um mesmo alimento (como carne moída, quibe, almôndega e hambúrguer) ser registrado ora em um órgão, ora em outro, o que pode confundir o consumidor e gerar insegurança no consumo do produto.

Já com relação às autoridades sanitárias, o conflito pode levar à insegurança jurídica. Em seus respectivos trabalhos, Carvalho ${ }^{40}$ e Lacerda-Filho ${ }^{41}$ apontam que esse conflito pode ser responsável por gerar duplicidade de fiscalização sanitária em um mesmo estabelecimento, o que é proibido pela Lei n. 1.283/1950. Por outro lado, pode ocorrer também omissão na atuação dos agentes públicos, o que é considerado crime de prevaricação, podendo ensejar-lhes detenção de três meses a um ano, além de multa ${ }^{42}$.

Com relação aos agentes fiscalizados, as lacunas legislativas também podem ser responsáveis por determinar confusão quanto a qual legislação seguir, visto que existe, muitas vezes, duplicidade de normatização sobre determinados processos produtivos $^{43}$. Por exemplo, mesmo antes da publicação das legislações municipais que permitiram a pré-moagem de carnes em açougues (Lei n. 16.386/2016, de São Paulo, e Lei n. 15.344/2016, de Campinas), muitos estabelecimentos já produziam o produto embasados na existência da Instrução Normativa n. 83/2003, editada pelo MAPA. No entanto, essa legislação aplica-se apenas a produtos fabricados na indústria, e não no comércio varejista, como delimita sua introdução.

Por fim, na opinião de Carvalho ${ }^{44}$, conflitos e embates políticos podem ocorrer entre entes fiscalizatórios, nos mais variados níveis de governo. A carne

\footnotetext{
${ }^{38}$ COSTA, Ediná Alves. Vigilância Sanitária e proteção da saúde. Direito sanitário e saúde pública, Brasília, v. 1, p. 179-203, 2003. Disponível em: http://bvsms.saude.gov.br/bvs/publicacoes/direito_san_v1.pdf. Acesso em: 23 jan. 2019.

${ }^{39}$ CARVALHO, Patrícia Borges. op. cit.

${ }^{40}$ Id. Ibid.

${ }^{41}$ LACERDA-FILHO, Francisco Pereira. op. cit.

${ }^{42}$ BRASIL. Decreto-Lei n. 2.848, de 7 de dezembro de 1940. Código Penal. Disponível em: http://www2.camara. leg.br/legin/fed/declei/1940-1949/decreto-lei-2848-7-dezembro-1940-412868-publicacaooriginal-1-pe. html. Acesso em: 23 jan. 2019. Deve-se ressaltar que o crime de prevaricação requer a ação dolosa do agente.

${ }^{43}$ CARVALHO, Patrícia Borges. op. cit.

${ }^{44}$ Id. Ibid.
} 
Competência dos órgãos da saúde e da agricultura na inspeção e fiscalização de açougues em São Paulo

pré-moída também é um exemplo disso, pois existem legislações municipais e estaduais, ainda vigentes, sobre esse mesmo assunto e em sentidos totalmente opostos (as municipais liberam a comercialização, e a estadual a proíbe).

Desse modo, é possível observar que, conforme opina Carvalho ${ }^{45}$, “a duplicidade de normatização confunde o consumidor, o setor regulado e os próprios agentes públicos federais, estaduais e municipais”. De acordo com essa autora, é imprescindível que se esclareça se, de fato, os setores ligados à agricultura possuem competência para fiscalizar produtos de origem animal. Em caso afirmativo, o início e o fim dessa competência devem ser melhor estabelecidos. O mesmo deve ser definido para os órgãos ligados à pasta da saúde. Essas definições possibilitariam uma atuação complementar dos órgãos, o que favoreceria a inspeção e fiscalização de produtos de origem animal no país.

\section{Pesquisa jurisprudencial no TJSP}

A pesquisa jurisprudencial, realizada no sítio eletrônico do Tribunal de Justiça do Estado de São Paulo (TJSP), evidencia que, na maioria das vezes, as ocorrências que chegam ao conhecimento do Poder Judiciário relacionam-se a questões tributárias. Assim, supermercados que contemplam a atividade de açougue solicitam direito a crédito fiscal por considerarem que o uso de energia elétrica nesse setor é realizado para atividades que envolvem industrialização de produtos. Embora algumas decisões julguem que o supermercado realize atividades mistas, de acordo com a legislação sanitária (Portaria CVS n. 01/2018, atualizada pela Portaria CVS n. 01/2020) e com as classificações da Concla ${ }^{46}$, o estabelecimento é caracterizado como pertencente ao ramo varejista. Por outro lado, evidenciou-se o entendimento de que atividades como preparo de carnes temperadas e colocação de embalagens a vácuo são consideradas, nesses mesmos julgados, atividades industriais ${ }^{47}$.

Assim, pode-se dizer que a questão da retirada das carnes de sua embalagem original, prática comum em açougues e supermercados, chega ao Poder Judiciário, ainda que de modo indireto. No entanto, não é a pertinência da realização dessa prática que é discutida, mas sim a ausência de rastreabilidade e segurança imputada aos produtos comercializados por esses estabelecimentos ${ }^{48}$.

\footnotetext{
${ }^{45}$ CARVALHO, Patrícia Borges. op. cit.

${ }^{46}$ INSTITUTO BRASILEIRO DE GEOGRAFIA E ESTATÍSTICA - IBGE. Comissão Nacional de Classificação CONCLA. Disponível em: https://cnae.ibge.gov.br. Acesso em: 19 jul. 2018.

${ }^{47}$ TRIBUNAL DE JUSTIÇA DO ESTADO DE SÃO PAULO. Apelação n. 0015743-47.2010.8.26.0019. Relator: Borelli Thomaz. DJ:10 out. 2013. Disponível em: https://esaj.tjsp.jus.br/cpopg/show.do?processo. codigo $=0 J Z$ ZAOC5B0000\&processo.foro=19\&processo.numero=0015743-47.2010.8.26.0019\&uuidCapt cha=sajcaptcha_6b1c40bdf5654935b7c2350ccd604e8f. Acesso em: 04 dez. 2019.

${ }^{48}$ TRIBUNAL DE JUSTIÇA DO ESTADO DE SÃO PAULO. Habeas Corpus Criminal n. 2103477-44.2019.8.26.0000. Relator:OsniPereira.DJ:24set.2019.Disponívelem:https://tj-sp.jusbrasil.com.br/jurisprudencia/765406109/ habeas-corpus-criminal-hc-21034774420198260000-sp-2103477-4420198260000/inteiro-teor765406121?ref=feed. Acesso em: 04 dez. 2019.
} 
Nessa celeuma, constatou-se o caso de um estabelecimento atacadista, segundo sua inscrição no Cadastro Nacional de Pessoa Jurídica (CNPJ), que é caracterizado pelos responsáveis como beneficiador e comercializador de carnes. No acórdão mencionado, a prática motivadora da ação era justamente a embalagem de carnes provenientes da indústria por estabelecimento caracterizado legalmente como atacadista. Nesse processo, alevanta-se a lesividade da ausência de informações necessárias nos rótulos dos produtos, mas, em nenhum momento, a pertinência da realização dessa atividade por estabelecimentos fiscalizados pela saúde é questionada ${ }^{49}$.

Com relação à carne temperada em espeto, embora novamente as ações judiciais se refiram apenas às questões tributárias, a consulta à jurisprudência mostra que há entendimento pacífico de que esse produto é reconhecido como industrializado $^{50}$. No entanto, não se leva em consideração a possibilidade legal (Decreto Estadual n. 45.248/2000) de que ele seja produzido em casas de carnes, ou seja, em comércios varejistas.

Com relação à carne moída, a pesquisa jurisprudencial mostra que já houve declaração de inconstitucionalidade da Lei Municipal n. 5.419/2018 ${ }^{51}$, no município de Pirassununga, que autoriza a pré-moagem na ausência do consumidor. $O$ fundamento do mencionado controle concentrado (ADI 2121513-37.2019.8.26.0000) baseia-se no fato de que essa lei não suplementa legislação estadual, estando em dissonância com seu texto, visto que faculta algo que, em verdade, é obrigatório (moagem à vista do consumidor) ${ }^{52}$.

Outras jurisprudências relevantes evidenciam a questão de fraude, já mencionada anteriormente. No ano de 2009, constatou-se o caso de um açougue no município de Marília que manufaturava carne bovina e suína utilizando etiquetas falsamente advindas de um frigorífico inspecionado pelo Ministério da Agricultura, Pecuária

\footnotetext{
${ }^{49}$ TRIBUNAL DE JUSTIÇA DO ESTADO DE SÃO PAULO. Apelação criminal n. 0103042-27.2014.8.26.0050. Relator: Nelson Fonseca Júnior. DJ: 07 nov. 2019. Disponível: https://esaj.tjsp.jus.br/cpopg/show. do?processo. .codigo=1E001RL6P0000\&processo.foro=50\&processo.numero=0103042-27.2014.8.26.00 50\&uuidCaptcha=sajcaptcha_a958fb19acb04038a12b519bfeb2a070. Acesso em: 04 out. 2019.

${ }^{50}$ TRIBUNAL DE JUSTIÇA DO ESTADO DE SÃO PAULO. Apelação n. 0611709-43.2008.8.26.0053. Relator: Vicente de Abreu Amadei. DJ: 06 mar. 2012. Disponível em: https://esaj.tjsp.jus.br/cpopg/ show.do?processo.codigo $=1 \mathrm{H} 000099 \mathrm{~B} 0000$ \&processo. foro $=53 \&$ processo. umero $=0611709-43.2$ 008.8.26.0053\&uuidCaptcha=sajcaptcha_3e6ea02ca2994d9a96bb0e260a4923d7. Acesso em: 04 dez. 2019.

${ }^{51}$ PIRASSUNUNGA. Lein. 5.419, de 11 de dezembro de 2018. Disponível em: https://leis.camarapirassununga. sp.gov.br/ged/leis/2018/5419.pdf. Acesso em: 05 dez 2019.

${ }^{52}$ TRIBUNAL DE JUSTIÇA DO ESTADO DE SÃO PAULO. Acórdão. Autos de Direta de Inconstitucionalidade n. 2121513-37.2019.8.26.0000. Relator: Antônio Carlos Malheiros. DJ: 18 set 2009. Disponível em : https://esaj.tjsp.jus.br/cposg/search.do?conversationld=\&paginaConsulta=0\&cbPesquisa=NUMPRO C\&numeroDigitoAnoUnificado $=2121513-37.2019 \&$ foroNumeroUnificado $=0000 \&$ dePesquisaNuUnifica $\mathrm{do}=2121513-37.2019 .8 .26 .0000 \&$ dePesquisaNuUnificado=UNIFICADO\&dePesquisa=\&tipoNuProcesso= UNIFICADO. Acesso em: 05 dez. 2019.
} 
Competência dos órgãos da saúde e da agricultura na inspeção e fiscalização de açougues em São Paulo

e Abastecimento ${ }^{53}$. Em 2016, o estabelecimento varejista foi registrado como entreposto de carne e derivados no Serviço de Inspeção do Estado de São Paulo (SISP) ${ }^{54}$.

Por fim, com relação aos derivados cárneos, vale ressaltar duas ocorrências. A primeira refere-se ao questionamento dos tributos exigidos na fabricação de hambúrguer ${ }^{55}$. Utilizando-se da definição legal apresentada pelo Ministério da Agricultura, Pecuária e Abastecimento (Instrução Normativa n. 20/2000) de que o hambúrguer é produto industrializado, a apelação referente à inexigibilidade do Imposto sobre Operações relativas à Circulação de Mercadorias e sobre Prestações de Serviços de Transporte Interestadual e Intermunicipal e de Comunicação (ICMS) foi negada judicialmente. A segunda ocorrência refere-se à comercialização de produtos impróprios ao consumo por estabelecimento que exercia a atividade de açougue. Nessa apelação, citou-se que a perícia concluiu, a partir da observação de indícios, que o estabelecimento realizava a salga de produtos de origem animal ${ }^{56}$, o que, embora não claramente conste em legislação sanitária, deve ser considerado, como já mencionado anteriormente, parte de um processo industrial, de acordo com o definido no artigo $4^{\circ}$, incisos I e II, do Decreto n. 7.212/2010.

Assim, verifica-se que as questões referentes à produção e à comercialização de produtos de origem animal que chegam ao Judiciário referem-se, na maioria das vezes, a questões tributárias. Nas hipóteses que envolvam questionamento sanitário, raramente leva-se em consideração a questão da pertinência da fabricação e da produção de alguns alimentos por açougues ou estabelecimentos atacadistas de carnes ou da realização de algumas práticas por esses tipos de estabelecimento.

\section{Soluções para o conflito}

Existem várias soluções possíveis para o conflito até então apresentado, sendo algumas mais simples e imediatas e outras, mais complexas e dificultosas. De acordo com Pereira e Moura ${ }^{57}$, a solução mais adequada, considerando-se os

\footnotetext{
${ }^{53}$ TRIBUNAL DE JUSTIÇA DO ESTADO DE SÃO PAULO. Apelação Criminal n. 0018059-62.2009.8.26.0344. Relator: Ivana David. DJ: 13 mai. 2014. Disponível em: https://esaj.tjsp.jus.br/cpopg/show.do?processo. codigo=9KY090DXN0000\&processo.foro=344\&processo.numero=0018059-62.2009.8.26.0344\&uuidC aptcha=sajcaptcha_a2535447d169418d96baaa5da83712f9. Acesso em: 05 dez. 2019

${ }^{54}$ SECRETARIA DE AGRICULTURA E ABASTECIMENTO. Coordenadoria de Defesa Agropecuária. Lista de estabelecimentos registrados no SISP/CIPOA/CDA. Disponivel em: https://www.defesa.agricultura.sp.gov. br/. Acesso em: 05 dez. 2019.

${ }^{55}$ TRIBUNAL DE JUSTIÇA DO ESTADO DE SÃO PAULO. Apelação n. 1004410-66.2014.8.26.0302. Relator: Antônio Celso Aguilar Cortez. DJ: 20 nov. 2016. Disponível em: https://esaj.tjsp.jus.br/cpopg/show. do? processo.codigo $=8$ E0000VRK0000\&processo. foro=302\&processo. numero=1004410-66.2014.8.26. 0302\&uuidCaptcha=sajcaptcha_3ffe8b8309c343558908994a45a152e5. Acesso em: 05 dez. 2019.

${ }^{56}$ TRIBUNAL DE JUSTIÇA DO ESTADO DE SÃO PAULO. Apelação criminal n. 0003387-19.2010.8.26.0084. Relator: Marco de Lorenzi DJ: 08/03/2012. Disponível em: https://esaj.tjsp.jus.br/cpopg/show. do? processo. codigo $=2 \mathrm{CYOA0} 2 \mathrm{M} 30000$ \&processo. foro $=84$ \&processo. numero $=0003387-19.2010 .8 .26 .0$ 084\&uuidCaptcha=sajcaptcha_06b0e11e1a3749a7893911544066bddb. Acesso em: 05 dez. 2019.

${ }^{57}$ PEREIRA, Gúbio Dias; MOURA, Luís Antônio de. op. cit.
} 
pontos de vista técnico e jurídico, seria a incorporação à Anvisa dos órgãos de inspeção de produtos de origem animal que pertencem atualmente ao MAPA, o que também ocorreria nas instâncias estaduais e municipais, de acordo com o princípio da descentralização do SUS. Essa medida, segundo os autores mencionados, tornaria as atividades desempenhadas pelo MAPA constitucionais e não cessaria o trabalho desse ministério, de grande importância à sociedade brasileira. Essa solução é também mencionada no trabalho de Carvalho ${ }^{58}$, que ainda esclarece a necessidade de revisão e reorganização das normas infraconstitucionais para compatibilizá-las às determinações constitucionais.

Outra solução possível, segundo Carvalho ${ }^{59}$ e Pereira e Moura ${ }^{60}$, é a propositura de emenda constitucional que modifique o artigo 200 , inciso VI, da $\mathrm{CF} / 88^{61}$, incluindo termos que mencionem a participação e a colaboração de órgãos da agricultura na inspeção de alimentos. Nesse caso, ainda de acordo com Carvalho ${ }^{62}$, as normas infraconstitucionais deveriam definir claramente os limites de atribuições de cada órgão, sendo que a competência da agricultura na inspeção e fiscalização de produtos cárneos terminaria logo após a morte do animal; a partir desse ponto, então, a atribuição passaria a ser dos órgãos de saúde pública. Pereira e Moura ${ }^{63}$ citam que, nesse caso, também deveria haver uma "extensa readequação das normas infraconstitucionais pertinentes".

Entretanto, data maxima venia aos entendimentos supracitados, não se trata de um fenômeno de inconstitucionalidade - seja por ação, seja por omissão -, mas sim de inércia por parte do legislador em elaborar normas infraconstitucionais a contento, que antevejam situações como as ora expostas e coíbam a notória guerra de competência que se vislumbra na hipótese. Isso porque a $\mathrm{CF} / 88$ não está a estabelecer questões de ordem operacional (em que pese seu caráter efetivo), e sim parâmetros em todas as suas normas, garantindo à população regramentos rígidos de observância obrigatória e que garantam às presentes e futuras gerações uma sadia qualidade de vida. Logo, não caberia quaisquer questionamentos acerca de possível Ação Direta de Inconstitucionalidade (ADI).

Desta feita, cabe tão somente à norma infraconstitucional operacionalizar os meios de concretização e organização de suas premissas, bem como de preceitos de cumprimento imediato, não restando qualquer defasagem técnica em seu teor. $\mathrm{O}$ artigo $200 \mathrm{da} \mathrm{CF} / 88$ traz expressamente que ao SUS compete, nos termos da lei, realizar ações de vigilância sanitária e epidemiológica e fiscalizar e inspecionar

\footnotetext{
${ }^{58}$ CARVALHO, Patrícia Borges. op. cit.

${ }^{59}$ Id.Ibid.

${ }^{60}$ PEREIRA, Gúbio Dias; MOURA, Luís Antônio de. op. cit.

${ }^{61}$ BRASIL. Constituição da República Federativa do Brasil de 1988. Disponível em: http://www.planalto.gov. br/ccivil_03/constituicao/constituicaocompilado.htm. Acesso em: 16 abr. 2021.

${ }^{62}$ CARVALHO, Patrícia Borges. op. cit.

${ }^{63}$ PEREIRA, Gúbio Dias; MOURA, Luís Antônio de. op. cit.
} 
Competência dos órgãos da saúde e da agricultura na inspeção e fiscalização de açougues em São Paulo

alimentos, compreendido o controle de seu teor nutricional, bem como bebidas e águas para consumo humano. Ora, a Carta Magna é cristalina ao determinar que a legislação infraconstitucional seria a responsável por tratar os meios e procedimentos necessários para o cumprimento de tais pontos, não cabendo, portanto, $\mathrm{o}$ questionamento de inconstitucionalidade. O ponto crítico desta discussão está no fato de a Lei n. 8.080/1990 (que dispõe sobre as condições para a promoção, proteção e recuperação da saúde, a organização e o funcionamento dos serviços correspondentes e dá outras providências) prever que a direção do SUS, na esfera federal, deve ser realizada pelo Ministério da Saúde, nada dispondo acerca do Ministério da Agricultura, Pecuária e Abastecimento. Logo, a Lei n. 7.889/1989, que dispõe sobre inspeção sanitária e industrial dos produtos de origem animal, acaba por ser juridicamente questionada, uma vez que traz em seu bojo ser de competência do MAPA, na esfera federal, a fiscalização de tais alimentos.

Afinal, se o MAPA não compõe o Sistema Único de Saúde, nos termos da Lei n. 8.080/1990, e se cabe ao SUS a realização das mencionadas fiscalizações, conforme assevera o texto constitucional, estaria o MAPA realizando atividades que não mais lhe pertencem. Tal celeuma apenas torna claro o fato de que também não se está diante de uma inconstitucionalidade por omissão, mas sim de uma lacuna legislativa ocorrida na criação dessa lei, haja vista não ter sido mencionado tal ponto, crucial para o deslinde da questão.

Com isso, o caminho mais adequado seria a propositura de um Projeto de Lei Infraconstitucional alterando a Lei n. 8.080/1990, com o fim de modificar a composição do SUS e delimitar competências de forma específica e tecnicamente adequada. Isso permitiria que ambos os ministérios trabalhassem de forma colaborativa e concorrente quanto ao tema específico da fiscalização alimentar, com atuação conjunta e estratégica que respeitasse as devidas delimitações nas esferas operacionais e técnicas de cada órgão.

A criação do Serviço de Inspeção Municipal por todo município também seria uma solução complementar possível. Embora o conflito legal ainda existisse, haveria, dentro do município, as duas possibilidades de fiscalização (a da saúde e a da agricultura). Além disso, no próprio diploma legal que criasse esse serviço municipal, deveria haver a delimitação das competências de atuação dos órgãos, $o$ que resolveria a questão ao menos no nível municipal. Nesse sentido, outra solução complementar possível seria a criação de normas municipais, dentro do âmbito de atuação da vigilância sanitária, que regulassem melhor a atividade de açougue. $\mathrm{Na}$ Portaria n. 2.619/2011, que rege as boas práticas de manipulação no município de São Paulo, por exemplo, foram incluídos artigos que restringem as atividades desempenhadas por açougues. Com isso as casas de carnes na capital paulista não podem, por exemplo, produzir preparações de carne moída, o que não está estabelecido na legislação estadual (Portaria CVS n. 05/2013). 
O estado de Santa Catarina adotou uma solução bastante interessante para, se não resolver definitivamente, ao menos amenizar a questão do conflito. Em 2016, foi publicada a Portaria Conjunta n. 264/2016 ${ }^{64}$, das secretarias estaduais de Saúde e de Agricultura e Pesca, com o propósito de tornar claros e objetivos às autoridades sanitárias e aos responsáveis por estabelecimentos de alimentos as exigências e os requisitos referentes à comercialização e à fiscalização de produtos de origem animal no estado de Santa Catarina. Essa legislação define e categoriza as atividades de açougues e entrepostos. Em seu texto legal, os açougues não têm permissão para produzir carnes temperadas ou realizar outras atividades industriais e são divididos em duas classes: o açougue tipo A possui permissão para porcionar, reembalar e rotular carnes e derivados já inspecionados na origem e deve ter responsável técnico pela atividade; já ao açougue tipo $\mathrm{B}$, a reembalagem e a rotulagem não são permitidas, não havendo necessidade de profissional técnico.

A mesma portaria cria os entrepostos em supermercados, aos quais são possibilitadas atividades de adição de temperos, condimentos e aditivos, ou seja, atividades de transformação da matéria-prima, além de outras, como fracionamento, porcionamento, embalagem e rotulagem. Esses entrepostos são fiscalizados pelo Serviço de Inspeção Estadual da Secretaria da Agricultura e Pesca ou pelos serviços municipais de inspeção.

Essa legislação catarinense estabelece que qualquer estabelecimento que comercialize carne e produtos cárneos deve garantir a rastreabilidade da peça original. Com relação à carne moída, a pré-moagem é proibida ao açougue tipo $\mathrm{B}$, mas não ao açougue tipo A e ao entreposto. Desse modo, a Portaria n. 264/2016 categoriza os estabelecimentos, permitindo maior manipulação aos entrepostos e limitando as atividades de açougues que não devem fabricar produtos novos.

Vale ressaltar que a iniciativa do estado de Santa Catarina se aproxima bastante do que é estabelecido pelo artigo 532 do Decreto Federal n. 9.013/2017. Nesse artigo, cita-se a atuação conjunta entre o Departamento de Inspeção de Produtos de Origem Animal e o órgão regulador da saúde para padronização de procedimentos relacionados à inspeção e fiscalização de alimentos.

Portanto, considerando as dificuldades enfrentadas face às legislações relacionadas às competências para fiscalização de produtos de origem animal, nossa orientação é no sentido de se apresentar competente Projeto de Lei Infraconstitucional modificando a Lei n. 8.080/1990, para o fim de alterar a composição do SUS e delimitar competências de forma específica e tecnicamente adequada, permitindo que os ministérios da Saúde e da Agricultura trabalhem de forma colaborativa e concorrente na fiscalização alimentar. Tal medida garantiria uma atuação conjunta e estratégica, respeitando as devidas delimitações operacionais e técnicas de cada órgão.

${ }^{64}$ SANTA CATARINA. Portaria n. 264, de 30 de março de 2016. Disponível em: http://www.vigilanciasanitaria. sc.gov.br/index.php/131-noticias/noticias-2016/782-publicada-portaria-conjunta-ses-sar-n-267-de-30de-marco-de-2016. Acesso em: 18 jan. 2019. 
Competência dos órgãos da saúde e da agricultura na inspeção e fiscalização de açougues em São Paulo

Embora seja um assunto de grande importância, a jurisprudência mostra que o conflito de normas em si raramente chega à esfera judicial, o que faz com que passe desapercebido. Geralmente, apenas as autoridades sanitárias se sentem lesadas pela existência dessa situação, exceto quando é tomada alguma ação que imponha restrições drásticas ao comerciante. No entanto, observa-se que, mesmo assim, raramente o setor empresarial busca ajuda no Poder Judiciário para rever seus possíveis direitos. Desta forma, é imprescindível que os conselhos de classe fomentem discussões para tornar a questão mais perceptível. Do mesmo modo, os debates em câmaras legislativas devem ser estimulados para que haja mudanças na legislação atual que solucionem o conflito. Caso contrário, além dos problemas já expostos, haverá a perpetuação desta problemática, que impõe altos riscos para a população, tendo em vista a possibilidade de produtos alimentares não serem devidamente fiscalizados em decorrência da ausência de regramentos efetivos e eficazes, gerando não apenas uma insegurança jurídica, mas, principalmente, sanitária.

\section{Considerações finais}

A existência de dois órgãos de inspeção e fiscalização para produtos cárneos e derivados, aliada à ausência de definição de conceitos e à falta de delimitação clara de competência entre esses órgãos, leva à existência de um conflito com implicações para agentes fiscalizatórios, consumidores e empresários do setor.

É possível depreender da análise da pesquisa desenvolvida para este artigo que o assunto é muito pouco divulgado na literatura científica, sendo apenas estudado por inspetores da vigilância sanitária ou por outros servidores públicos cujo trabalho é diretamente afetado pela falta de clareza das legislações existentes. As autoridades sanitárias de todo o país geralmente são as maiores prejudicadas pela existência desse conflito, pois lidam com ele diariamente ao exercer suas funções. Dentre esses profissionais, destacam-se os médicos veterinários, geralmente designados para inspecionar e fiscalizar os comércios varejistas de carne - ramo econômico no qual o conflito é bastante perceptível. Além dessa classe, responsáveis técnicos e consultores de indústrias de alimentos e de serviços de alimentação também estão frequentemente envolvidos, mas não sentem o peso da tomada de decisões baseada em legislações conflitantes ou em limbo legislativo, ou seja, em insegurança jurídica.

Desse modo, embora raramente produza efeitos na esfera judicial, esse conflito necessita ser solucionado e, para isso, existem diversas condutas que podem ser adotadas. Entre as medidas sugeridas, algumas podem ser mais facilmente executadas - como a alteração da Lei n. 8.080/1990 ou a criação de legislações infraconstitucionais que estabeleçam limites mais claros entre as atividades de açougue e entrepostos - ou mais complexas - como a incorporação à Anvisa da atividade desempenhada pelo MAPA. Assim, o assunto precisa tornar-se mais perceptível para que haja discussões produtivas que direcionem esse conflito para uma resolução. 
Por fim, não se pode olvidar da importância do tema para a população, tendo em vista que os impasses mencionados, por trazerem insegurança jurídica ao processo fiscalizatório, acabam por torná-lo temerário, embora o adequado processo fiscalizatório seja trazido como garantia constitucional.

\section{Referências}

ABRANTES, Maria Rociene; SOUSA, Ana Carina Praciano; ARAÚJO, Nikolay Kiev Saraiva de; SOUSA, Êlika Suzianny de; OLIVEIRA, Adriene Rosceli Menezes de; SILVA, Jean Berg Alves da. Avaliação microbiológica de carne de charque produzida industrialmente. Arquivos do Instituto Biológico, v. 81, n. 3, p. 282-285, 2014. Disponível em: http://www.scielo.br/ pdf/aib/v81n3/1808-1657-aib-81-03-00282.pdf. Acesso em: 05 dez 2019. https://dx.doi. org/10.1590/1808-1657000942012.

BÁNKUTI, Ferenc Istvan. Entraves e incentivos ao abate clandestino de bovinos no Brasil. 2002. Dissertação (Mestrado) - Programa de Pós-Graduação em Engenharia de Produção da Universidade Federal de São Carlos, 2002. Disponível em: http://www.gepai.dep.ufscar. br/pdfs/1088521715_Ferenc_OK.pdf.

BONFADA, Daniele Hübner; KINDLEIN, Liris; VILARINHO, Rita Cássia; BERGMANN, Guiomar Pedro. Presença de sulfito de sódio e sua influência nas características físico-químicas e microbiológicas de carnes bovinas moídas resfriadas moídas resfriadas. Acta Scientiae Veterinariae, v. 40, n. 2, p. 1036, 2012. Disponível em: http://www.ufrgs.br/actavet/40-2/ PUB\%201036.pdf. Acesso em: 03 dez. 2019.

CARVALHO, Patrícia Borges. Conflito de competências na fiscalização de alimentos de origem animal no Brasil: uma análise da legislação em vigor no Brasil. Revista de Direito Sanitário, São Paulo, v. 5, n. 1, p. 18-39, mar. 2004. Disponível em: http://www.revistas.usp.br/rdisan/article/ view/80885. Acesso em: 19 jul. 2018. https://doi.org/10.11606/issn.2316-9044.v5ilp18-39.

COSTA, Ediná Alves. Vigilância Sanitária e proteção da saúde. Direito sanitário e saúde pública, Brasília, v. 1, p. 179-203, 2003. Disponível em: http://bvsms.saude.gov.br/bvs/publicacoes/ direito_san_v1.pdf. Acesso em: 23 jan. 2019.

INSTITUTO BRASILEIRO DE GEOGRAFIA E ESTATÍSTICA - IBGE. Comissão Nacional de Classificação - CONCLA. Disponível em: https://cnae.ibge.gov.br. Acesso em: 19 jul. 2018.

INSTITUTO BRASILEIRO DE GEOGRAFIA E ESTATÍSTICA - IBGE. Comissão Nacional de Classificação - CONCLA. CNAE-Subclasses. Disponível em: https://concla.ibge.gov.br/ busca-online-cnae.html? view $=$ subclasse $\&$ tipo $=$ cnae $\&$ versao $=10 \&$ subclasse $=4722901$. Acesso em: 19 jul. 2018.

LACERDA-FILHO, Francisco Pereira. Conflito de atribuições no controle e fiscalização de alimentos de origem animal no Brasil, a luz da Constituição Federal. Cadernos Ibero-americanos de Direito Sanitário, v. 5, n. 4, p. 27-41, dez. 2016. Disponível em: https:// www.cadernos.prodisa.fiocruz.br/index.php/cadernos/article/view/251. Acesso em: 19 jul. 2018. http://dx.doi.org/10.17566/ciads.v5i4.251. 
Competência dos órgãos da saúde e da agricultura na inspeção e fiscalização de açougues em São Paulo

MANTILLA, Samira Pirola Santos; MANO, Sergio Borges; VITAL, Hélio de Carvalho; FRANCO, Robson Maia. Atmosfera modificada na conservação de alimentos. Revista Acadêmica Ciências Agrárias e Ambientais, v. 8, n. 4, p. 437-448, 2010. Disponível em: https:// periodicos.pucpr.br/index.php/cienciaanimal/article/viewFile/11000/10397. Acesso em: 05 dez. 2019.

MIRELLES, Hely Lopes. Direito administrativo brasileiro. 42. ed. São Paulo: Malheiros, 2016.

MOURA, Luís Antônio. Qualidade bacteriológica de carcaças de aves, sob diferentes condições das operações de abate, comercializadas em feiras urbanas do Distrito Federal. 2012. Tese (Doutorado) - Escola de Veterinária e Zootecnia, Universidade Federal de Goiás, Goiânia, 2012.

PEREIRA, Gúbio Dias; MOURA, Luís Antônio de. Conflito de competências entre os Ministérios da Saúde e da Agricultura na fiscalização de produtos alimentícios no Brasil. Revista Tempus- Acta de Saúde Coletiva, v. 7, n. 1, p. 197-210, 2013. Disponível em: http:// www.tempusactas.unb.br/index.php/tempus/article/view/1287. Acesso em: 19 jul. 2018. http:// dx.doi.org/10.18569/tempus.v7i1.1287.

TESSER, Elisa Scheid. O uso de diferentes tipos de embalagem na conservação de carnes bovinas. 2009. Monografia (Graduação) - Faculdade de Veterinária, Universidade Federal do Rio Grande do Sul, Porto Alegre, 2009.

\section{Agradecimentos}

Ao Grupo Estratégico de Vigilância de Alimentos (GVA) da Prefeitura Municipal de Campinas/SP.

Patrícia Rossi Moriconi - Mestrado em Ciências pela Faculdade de Medicina Veterinária e Zootecnia da Universidade de São Paulo (FMVZ-USP); graduação em Medicina Veterinária pela FMVZ-USP. Atuou como Médica Veterinária Autoridade Sanitária no Setor de Vigilância Sanitária de Alimentos, da Prefeitura Municipal de Campinas, entre os anos de 2013 a 2018. Campinas/SP, Brasil.E-mail: patricia.moriconi@usp.br.

Karina Moriconi - Especialização em Direito Civil pela Universidade Presbiteriana Mackenzie (UPM); graduação em Direito pelo Centro Universitário de Assunção (Unifai). Advogada. São Paulo/SP, Brasil. E-mail: karinamoriconi@kappajur.com.br 